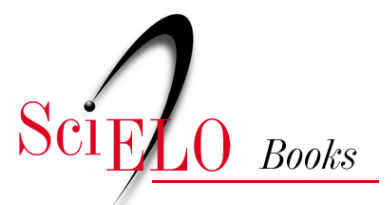

\title{
História do Dr. Carlos Chagas Filho (15 de setembro de 1999)
}

\author{
Virgínia Schall
}

\section{SciELO Books / SciELO Livros / SciELO Libros}

SCHALL, V. História do Dr. Carlos Chagas Filho (15 de setembro de 1999). In: Contos de Fatos: histórias de Manguinhos [online]. Rio de Janeiro: Editora FIOCRUZ, 2001, pp. 155-168. ISBN: 97885-7541-614-3. Available from: doi: 10.7476/9788575416143.0014. Also available in ePUB from: http://books.scielo.org/id/hdq6f/epub/schall-9788575416143.epub.

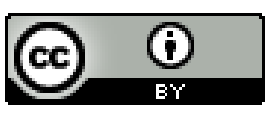

All the contents of this work, except where otherwise noted, is licensed under a Creative Commons Attribution $\underline{4.0 \text { International license. }}$

Todo o conteúdo deste trabalho, exceto quando houver ressalva, é publicado sob a licença Creative Commons Atribição 4.0. 


\title{
História do Dr. \\ Carlos Chagas Filho
}

(15 de setembro de 1999)

\author{
Wagner, \\ Verzeit! Es ist ein gross Ergetzen, \\ Sich in dem Geist der Zeiten zu versetzen; \\ Zuschaven, wie vor uns ein weiser Mann gedacht, \\ Und wie wir's dann zulezt so herrlich weit \\ gebracht.
}

Johann Wolfgang Goethe, Fausto ${ }^{40}$

\begin{abstract}
omeço a transcrição desta entrevista com uma frase de Goethe, em sua própria língua, o alemão, homenagem que faço ao Prof. Carlos Chagas, que, infelizmente, não pôde ler o meu texto, pois enquanto eu ainda trabalhava nele, veio a notícia do seu falecimento. Por que o alemão? Como conta o próprio Prof. Carlos Chagas em seu livro $M e u P a{ }^{41}$ o alemão foi a sua primeira língua, para desespero do seu avô, já que a $\mathrm{Fa}$, apelido de sua babá alemã, demorou a aprender português e falava em alemão com o menino. No mesmo livro, ele revela ainda que com ela leu o primeiro livro importante de sua vida: OSofrimento doJovem Werther, a obra mais simples de
\end{abstract}

\footnotetext{
${ }^{40}$ Diálogo entre Fausto e o discípulo Wagner, do livro Fausto, de Goethe. Na tradução de Silvio Meira (segundo este, ao pé da letra): Perdoai! É um grande prazer/No espírito do tempo mergulhar/E contemplar, como se estivesse perante nós o pensamento de um sábio.

${ }^{41}$ CHAGAS FILHO, C. Meu Pai. Rio de Janeiro: Casa de Oswaldo Cruz/Fiocruz, 1993.
} 
Goethe, "se assim se pode dizer". E por que escolhi essa frase? Porque nela está contido o sentido que gostaria de poder expressar e dar a conhecer aqui: o pensamento de um sábio, de alguém que transcende quaisquer palavras com que se queira traduzi-lo, tamanha a efervescência de sua mente ágil, culta, plena de memórias e vivências riquíssimas. $\mathrm{E}$ de alguém iluminado pelo humanismo e pela fé, em Deus e na ciência - as quais compatibilizava harmoniosamente -, bem como pela cordialidade e elegância com que a sua presença nos brindava.

Conheci o Prof. Carlos Chagas em 1986, como aluna do curso de metodologia científica, disciplina da pós-graduação em biofísica. Encontreio pela primeira vez no corredor do instituto. Não sabia quem era, mas não poderia deixar de notar aquele senhor vestido com apuro, um terno de linho bege, gravata, cinto, sapatos e meias combinando, de uma elegância sóbria, altiva, temperada por uma serenidade no andar e na expressão. Quando ele se apresentou como professor, logo percebi que teríamos um curso especial. $E$ assim foi. Eram aulas magníficas, e enorme o prazer de ir ao Fundão ouvir as suas lições entremeadas de histórias da ciência, relatos vívidos de um espectador e personagem de tantos fatos importantes no caminho da ciência no século XX. Em sua rica vida profissional, pôde conhecer e se relacionar com alguns dos mais importantes cientistas desse século, e nos dava o testemunho de descobertas e a descrição dos laboratórios freqüentados, assim como das inúmeras reuniões e eventos dos quais participou. Era como se estivéssemos assistindo a um filme, tamanha a fidelidade das descrições, dos detalhes, e eu, já dada ao sonho e à fantasia, podia mesmo sentir cheiros e atmosferas, quase me transportando aos cenários narrados. E nesse ambiente de uma verdadeira e prazerosa educação científica, éramos estimulados a refletir sobre o nosso próprio percurso e a nossa própria prática. Foi com uma motivação profunda que eu me dediquei à monografia de final de curso, escrevendo sobre a criatividade científica, o que me conduziu a um largo passeio pela literatura da área, da qual nunca mais me separaria, pois o tema continua a me interessar sempre. 
Algumas poucas vezes tornei a vê-lo e agora, recentemente, tive o privilégio de poder conversar com ele, em sua casa, num fim de tarde de uma primavera chuvosa. A casa, grande como poucas restam na orla da zona sul carioca, respira arte e cultura. Desde a sala de entrada, onde peças de antiquário convivem com belas telas, os livros se fazem presentes, como alguns, dispostos sobre a mesa de centro, em que se pode mergulhar na vida e na obra de grandes pintores. Após breve espera, fui convidada a subir em um pequeno elevador que me levou ao seu escritório de trabalho. Um ambiente acolhedor, latejando memórias de inúmeros lugares e da família nos tantos retratos ali dispostos com extremo bom gosto.

O tempo da conversa não foi longo, duas horas ou um pouco mais, mas a viagem nela empreendida atravessou décadas, talvez séculos. Transcrevo a seguir parte do que foi possível gravar, já que muito mais pude ouvir e agora posso guardar, lembranças suaves de alguém que atingiu a plenitude como expressão do que de mais humano (e transcendente) temos dentro de nós.

\section{Memórias de Manguinhos}

Nem será de outro modo, senão nos laboratórios e nos institutos de pesquizas exprimentaes, nomanejodomethodobiologicoedatechnicaphysico-dimicamodernas quemaisseesclaresa apathologia humanaemelhorseiluminem oslargosdomínios damedicina scientifica.

Carlos Chagas, 1917

A história que eu sei de cor é a história do meu pai. Mas essa eu já contei em livro. Atualmente eu estou fazendo um pequeno discurso para uma homenagem que vou receber em Manguinhos, o Prêmio Oswaldo Cruz, no dia $1^{\circ}$ de outubro. São muitas as lembranças. Estou imaginando uma porção de coisas. Mas está difícil selecionar. Então, quais são as histórias que eu posso contar a você?? 
Talvez alguns aspectos da história de Manguinhos. Uma das coisas, por exemplo, que eu sempre digo, na história de Manguinhos, que fizeram a grandeza do instituto, foi a qualidade dos serventes, dos auxiliares. E pouca gente sabe disso. Todos sabem o nome do meu pai e de outros chefes de laboratório, mas sem o pessoal que fazia o cotidiano, muito não teria sido possível. Eles eram sujeitos fabulosos. Eu, por exemplo, trabalhei com um mecânico, Júlio Grimaldi, que fez um dos aparelhos mais complicados de física que se podem fazer, para mim. Infelizmente, eu não pude continuar pesquisando com este aparelho, fiz só uns ensaios que deram certo, porque tive de fazer concurso para a Faculdade de Medicina, que era uma virada naquela ocasião.

Lá em Manguinhos, eu já trabalhava com a biofísica, que se chamava físico-química biológica, com Carneiro Felippe, principalmente. Eu fiz uma grande trajetória em Manguinhos, comecei trabalhando com anatomia patológica, depois fui para o Laboratório de Fisiologia do Miguel Ozório. Miguel Ozório de Almeida era uma pessoa extremamente interessante. Eu entrei para o laboratório do Miguel, quando o Haity [Moussatché] saiu. O Haity era interno do Hospital Evandro Chagas, que na época se chamava Hospital Oswaldo Cruz, e meu pai deixava ele morar lá, onde podia viver. Ele era uma pessoa extraordinária, fantástica. Eu tenho pena de ter conhecido pessoas que as outras pessoas não conheceram. E de não ter conhecido outras, como alguns autores de certos livros. Hoje eu estou lendo um livro que, só pela primeira página, verifiquei que é um livro maravilhoso, de um autor francês. O livro se chama Gabriel, sobre o anjo Gabriel, extraordinário.

Agora, o que eu posso te contar? A minha vida foi relativamente muito simples. Eu tive muita sorte. Nasci em um berço de ouro intelectual. Minha casa era cheia de gente interessante, franceses, alemães, todos que passavam por aqui iam ficar em minha casa. A casa dos meus pais era muito grande, na rua Paissandu. Uma casa que meu pai tinha comprado. Na verdade, quem comprou foi minha mãe: quando meu pai foi ao Amazonas, ficou lá dois anos, ele ganhou uma soma importante, e aí minha mãe resolveu 
comprar rapidamente a primeira casa boa que encontrou, porque ele estava ameaçando dar tudo o que tinha recebido para o instituto. Antes que ele fizesse isso, quando menos esperava, estava feito o negócio. Era uma casa grande, 14 metros de frente, 67 de fundo, uma verdadeira chácara, com jamelões, abacateiros, goiabeiras, plantas, orquídeas e tantas outras flores cultivadas pela minha mãe. De modo que todo mundo me pergunta: "Como foi a sua vocação para cientista?" Na verdade, eu não tinha vocação para cientista, eủ não tinha saída, não tinha como não ser. Então fui me encaminhando, fiz um curso em Manguinhos, que naquela época era realmente duro de se fazer, levava quase dois anos, estudando a semana inteira, em contato com grandes mestres do instituto. Ao mesmo tempo, eu trabalhava no Hospital São Francisco de Assis, onde arranjei meu primeiro emprego, que foi de assistente de necrotério - fazia autópsias -, e aprendi muito. Tinha uma certa dificuldade quando a lesão anatômica não correspondia ao que os clínicos achavam, eles protestavam. Queriam que a gente arranjasse um jeito de botar o achado anatômico de acordo com as opiniões deles.

Depois saí de lá e fui trabalhar em Manguinhos, meu pai com uma certa, digamos, advertência, porque o pessoal não queria que eu fosse contratado, pois achavam que eu era muito moço, e meu pai me contratou assim mesmo. E eu fui trabalhar com o Carneiro Felippe. Carneiro Felippe era uma pessoa extraordinária, uma competência, sabia tudo muito bem. Ele fazia físicoquímica. Foi ele que realizou a primeira montagem de um aparelho para medir $\mathrm{pH}$ no Brasil. Ele próprio reuniu as peças, foi uma criação dele. Ele era engenheiro de minas. Ele se formou na Escola de Minas de Ouro Preto. Carneiro Felippe não conseguiu ganhar a vida em Belo Horizonte, ele tinha muitos filhos, então foi para São João del-Rei, uma das grandes termas de Minas. Na época, o Raul Soares, que era governador de Minas Gerais, criou um laboratório de medidas industriais e, nele, Carneiro Felippe foi trabalhar com raios $\mathrm{X}$, ele tinha muito conhecimento de raios $\mathrm{X}$. Numa ocasião, meu pai foi a São João del-Rei, conheceu o Carneiro Felipe e o convidou para trabalhar em Manguinhos. 
Em Manguinhos, Carneiro Felippe trabalhava para muita gente, de modo que ele ia inclusive aos sábados e domingos. Ele era associado a outros pesquisadores, era como um consultor para os outros. Nós ficávamos em Manguinhos e saíamos de noitinha. De noitinha, eu digo sempre isso, no momento em que a Estrela Dalva começa a brilhar. Naquela meia-luz, Carneiro Felippe e eu tirando pedras do chão e ele explicando qual era a pedra, o que cada pedra continha, falando sobre a cristalização dela. Depois, o céu também: ele olhava para o céu e dizia, com a maior tranqüilidade, ali é a constelação tal, a estrela tal. Não dizia só isso; acrescentava: tem cinco graus de luminescência na escala tal. Ele era um sujeito extraordinário. Durante muito tempo ele foi um alimentador cerebral de Manguinhos. Eu trabalhava com ele no chamado Pavilhão do Quinino e durante o dia as medidas que estávamos fazendo eram interrompidas, pois inúmeros pesquisadores do IOC vinham perguntar a ele, que não era nem médico nem biólogo, era físico-químico, sobre várias coisas. Ele sabia tudo, sabia literalmente tudo. Uma coisa extraordinária. Tanto assim que ele foi um aluno tão brilhante na Escola de Minas que tiraram um retrato dele, quando ele se formou, na congregação. Eu tenho por ele uma gratidão, uma reverência. Foi uma das três grandes pessoas da minha vida. Tanto que, quando ele morreu, eu fiz um discurso na Academia de Ciências, tinha pouca coisa por dizer, em termos de trabalhos publicados, apenas contei o que eu sabia dele, o quão extraordinário tinha sido.

A outra pessoa foi Miguel Ozório. Ele era um homem muito bonito, pelo menos ele se considerava muito bonito, tinha uma barba linda. Mais tarde eu descobri que a barba, na realidade, escondia as marcas da acne. Era extraordinário, sabia matemática tanto quanto o Felippe, sabia física, sabia química - praticamente eram duas figuras assim, excepcionais, e aliás se tornaram muito amigos. Todos dois convidados pelo meu pai. Meu pai achou que no IOC estava faltando uma coisa nova, então ele trouxe o Miguel Ozório para a fisiologia e o Carneiro Felippe para a físico-química. Miguel era uma pessoa interessante, ele sabia falar francês tão bem, que uma vez eu assisti a uma conferência dele no Palais de la Découverte, em Paris, e custei 
a convencer um francês amigo meu de que ele não era francês. Ele tinha mania de automóvel. Ele morava no Alto da Tijuca. Quando chegava lá, tirava o relógio, a primeira coisa que dizia era: "Desta vez eu levei 17 minutos", por exemplo. Tempo bom aquele. Depois de Manguinhos, a gente ia para a cidade tomar uma bebidinha, naquela ocasião era chope, ninguém bebia uísque não, num daqueles quatro bares que tinha no Hotel Avenida Central, na Rio Branco, onde hoje é um centro comercial com o mesmo nome. Depois a gente ia comer alguma coisa num café-restaurante chamado Heim, na rua da Assembléia. Eu conto isso no meu discurso. Quando nós íamos para a sessão da Academia de Ciências - a Academia não tinha sede naquela época, e as sessões eram feitas na sala da Congregação da Escola Politécnica -, iam para lá os cientistas todos, ou um grupo de uns cinco ou seis, para tomar um chopezinho da Brahma. E eu, ainda muito jovem, mas muito metido, abelhudo, como eu digo, ficava ali assistindo e conversando. Eu era muito cuidadoso, não dava palpite nenhum, mas ouvia tudo, registrava tudo, era muito bom. Todos os dias que eu passei em Manguinhos eu aprendi muito. Eu saí de Manguinhos porque achei que, primeiro, não tinha alunos, Manguinhos não tinha alunos naquela época. Depois, eu queria levar a pesquisa científica para a universidade. E aí houve um concurso e eu fiz.

Naquele tempo, destacaram-se em Manguinhos os trabalhos do Aragão, do Neiva, do Costa Lima, do Gomes de Faria, todos muito importantes. Tem um fato muito engraçado sobre o Faria. Um dia eu estava estudando sobre uma epidemia de febre amarela aqui no Rio. $\mathrm{E}$ os amarelentos iam todos para Manguinhos, para o Hospital Oswaldo Cruz, hoje Hospital Evandro Chagas. Aí eu passei, acho que de sábado para domingo, fazendo uma preparação dificílima de fígado de amarelentos. O doente tinha morrido, eu o havia autopsiado e tinha separado a víscera para examinar. Montei uma técnica nova, achei que estava perfeita e levei para o Gomes de Faria. Era um domingo, e o único que estava lá era ele, para quem eu mostrei a lâmina. Ele olhou, olhou, eu achando que minha lâmina estava uma maravilha, ele jogou fora. Então eu vi o que é fazer ciência. Eu vi que 
ciência você tem de repetir, repetir, repetir e, principalmente, não se convencer de que o que você fez está esplêndido. Eu, então, voltei para fazer novas lâminas, e ao fim de uns vinte ou trinta ensaios, retornei e mostrei de novo ao Gomes de Faria, que desta vez admitiu estarem boas.

Havia ainda em Manguinhos certas pessoas interessantíssimas. Havia, por exemplo, o Ângelo Moreira da Costa Lima, que na época era o maior entomologista do mundo e um trabalhador em serviço incrível. Chegava entre 7 e 8 horas em Manguinhos e saía às 7, 8, 9 horas da noite. Sempre metido no laboratório, você não via ele fora do laboratório nunca. Esse trabalho dele, por exemplo, está compendiado em seis volumes, não sei mais como se chama - acho que Insetos do Brasil, não sei ao certo. Ele era um homem bonachão, agradabilíssimo: toda vez que eu ia lá, ele me dava um café, mas tinha sempre gente conversando com ele. O laboratório dele era no primeiro andar; quando se sobe a escada a partir do pátio, dobra-se à direita e na última porta era o dele. Até hoje tenho a imagem nítida dessas coisas. Tinha também uma pessoa que sabia loucamente sobre parasitologia, que era o Aristides Martins da Cunha. Ele tinha uma voz bitonal, falava de um jeito que tornava dificílimo nós nos mantermos sérios nas aulas. O que ele sabia de parasitologia era inacreditável.

Em Manguinhos, você tem três pontos: Oswaldo Cruz, que reuniu o melhor grupo de cientistas que você possa imaginar; os auxiliares, que faziam instrumentos e eram técnicos de laboratório maravilhosos; e a biblioteca. A biblioteca era surpreendente. Eu li na biblioteca de Manguinhos as memórias de todos os grandes físicos daquela ocasião, prêmios Nobel etc., publicadas nos Annalen der Physik, publicação alemã. A edição completa desses anais de física estava na biblioteca de Manguinhos. Oswaldo Cruz comprou a biblioteca por telégrafo, sem ter dinheiro. Ele tinha muita liberdade para fazer as compras. E tinha ousadia, arranjou um crédito especial, sabia que era importante. Só quem viveu, mergulhou na biblioteca pode imaginar o que era aquilo. E havia o Overmeer, um holandês. Ele era um bibliotecário mesmo, um verdadeiro policial, o guardião da biblioteca, 
verificava o que estava na mão de cada um; cada vez que saía alguém, qualquer que fosse o nível do pesquisador, tinha de mostrar o que levava.

Uma coisa que me encantava muito quando eu era menino e ia a Manguinhos era ir ao Laboratório do Lutz. O Lutz- eu tinha duas razões para vero Lutz, ou mesmo três: primeiro, porque o servente que o auxiliava era um homem que eu adorava, chamado Joaquim Venâncio, ele era filho de uma escrava de minha avó. Era um dos homens mais finos que eu tenho encontrado, uma voz suave, e como ajudava todo mundo! Ele sempre me levava para ver os animais, principalmente batráquios, que o Lutz estudava. Dizem que o Lutz era tão inteligente que podia classificar um sapo pelo coaxar. Corria isso. Quando eu chegava lá, ele sorria e imediatamente punha-se a falar alemão comigo, para saber se eu tinha ou não esquecido a língua. Todas as vezes!

De Manguinhos a nossa conversa fluiu para o Instituto de Biofísica, que marca outra etapa da vida do Prof. Carlos Chagas. O assunto começou motivado pela minha curiosidade sobre as suas pesquisas com peixes elétricos, especialmente o poraquê, com o qual eu também trabalhei no início de minha vida científica, no Laboratório de Neurofisiologia do Instituto de Ciências Biológias (ICB/UFMG), chefiado pelo Prof. Dr. Fernando Pimentel de Sousa.

\section{Memórias do Instituto de Biofísica}

Como é que eu fui me interessar por peixe elétrico? É o seguinte: eu fui para Paris logo que tirei a cátedra. Fui por conta própria, auxiliado pelo meu sogro - eu nunca tive bolsa. Chegando lá, havia uns seminários nas quintas-feiras. E, num deles, eu vi o que era um torpedo. Torpedo é um peixe elétrico de água salgada. E fiquei interessadíssimo por ele. Quando cheguei aqui, pensava que todo pesquisador de um país em desenvolvimento deve escolher como tema, quando possível, um modelo local. E eu fiquei na dúvida entre a preguiça e o peixe elétrico. A preguiça eu deixei em pouco 
tempo, porque era muito difícil de capturar, difícil de manter no biotério, mais perigosa do que o peixe elétrico, ela avança. $\mathrm{Na}$ ocasião, o Joaquim Rôla, que era dono do Cassino da Urca, um dos lugares importantes do Rio de Janeiro de então, encomendou uma série de peixes do Amazonas e fez uma exposição no salão de entrada do cassino. E dentre eles estava o poraquê - eu achei que ali estava o bicho que eu queria. Então, eu fui ao Rôla e ele, que era de Minas, me ofereceu quantos peixes eu quisesse. Eu achei que o poraquêera o modelo ideal para a biofísica - porque vocêtem transformação de energia química do órgão em energia elétrica da descarga. Que é exatamente um dos objetivos da biofísica, o estudo das transfor-mações energéticas. Então comecei a trabalhar com o peixe elétrico e havia um russo alemão, o Sr. Bernardo Maiman, que tinha se instalado no Brasil e, como ictiologista amador, trazia da Amazônia e fornecia peixes elétricos - que exercem sobre as pessoas uma atração fantástica - para circos. Me pus em contato com ele, que começou a me fornecer os peixes. E aí comecei a trabalhar com o peixe elétrico e foi em torno do peixe elétrico que eu consegui desenvolver o Instituto de Biofísica. Foram sendo montadas a seção de bioquímica, a seção de fisiologia, uma seção de histologia e, finalmente, o microscópio eletrônico veio como uma consequiência de estudar o peixe elétrico.

$\mathrm{Eu}$, naquela época, não conhecia nada de peixe, e a primeira coisa que fiz foi procurar um professor de anatomia da Escola de Agronomia, na Veterinária, para que ele dissecasse e eu visse como era o órgão elétrico. Sabia da existência do órgão elétrico, mas nunca tinha visto um. Esse rapaz, Prof. Werther Duque Estrada Bastos, foi um benemérito em minha carreira, ele me mostrou e eu aprendi exatamente como era a anatomia do órgão elétrico por meio de uma análise citológica. No peixe elétrico, o órgão elétrico se constitui de três porções: a maior, dorsal; uma menor, que é mais fina embaixo; e uma terceira, que é quase só o fim do órgão, que vai mais ou menos da guelra à cauda. A descarga é produzida por excitação do órgão: tanto uma excitação visual ou tátil quanto uma simples variação da pressão produzem a descarga. Não é fácil provar que seja um órgão de 
comunicação; eu mesmo tentei muito estudar isso, mas é muito difícil. Mas tem de ser um órgão de comunicação, tem de ser. Eu, aliás, tenho uma experiência muito interessante. Uma vez eu fui convidado para dar uma conferência na Academia de Fisiologia da Inglaterra. Eles já tinham trabalhado com o órgão elétrico, mas não tinham chegado a nada e souberam dos meus resultados daqui. Eu fui, um anfiteatro repleto, houve uma coisa curiosa. Eles me pediram para chegar dez minutos antes e eu cheguei, mas qual não foi o meu desprazer! Me deixaram sozinho, trancado num escritório. Eu fiquei ali sem entender bem o que acontecia, e na hora da conferência eles vieram abrir e me levaram para o anfiteatro cheio. Depois é que eu soube que em uma das primeiras conferências feitas para aquela academia, o conferencista, que era fantástico, tinha sumido na hora de se apresentar. Como bons ingleses, eles nunca mais quiseram correr esse risco. Foi engraçado. Mas o verdadeiro risco que eu corri foi que, durante a conferência, me deram um peixe, trouxeram um tanque e eu comecei a repetir tudo que eu queria que o peixe fizesse. E ele não errou uma única vez, o que é uma sorte fantástica, e a minha conferência foi um sucesso. Ao lado de uma tela, coloquei um osciloscópio catódico, para raios catódicos, para registro da descarga, de modo que foi muito bom. Eu fiquei com muito medo de algo sair errado e depois que eu saí eles brincaram, dizendo que tinham me trancado por causa disso.

Em relação aos estudos feitos no Instituto de Biofísica, destaco a depressão alastrante, muito bem estudada lá, como uma das maiores descobertas feita por um brasileiro, o Prof. Aristides Pacheco Leão. Foi uma das linhas mestras, como a do peixe elétrico também foi. Ele verificou que, cada vez que havia uma excitação no cérebro dos animais colocados para experimentação, havia uma redução importante da altura das ondas elétricas produzidas pelo cérebro. Ele estava nos Estados Unidos e veio para o Instituto de Biofísica, e eu tive muita sorte de novo, pois pude contratá-lo. OProf. Wurnser, pesquisador francês que tinha sido meu mestre e viera trabalhar aqui, havia sido chamado pelas forças do De Gaulle para prestar serviços na França. O seu lugar ficou livre e, nessa ocasião, chegou 
- Aristides, então eu pude contratá-lo imediatamente. Diga-se de passagem que contratar naquela época era bem mais fácil do que hoje. Aliás, eu não posso deixar de dizer que fui muito ajudado pelo Guilherme Guinle. Não existe outro no Brasil. Você imagina que o Evandro, meu irmão, havia construído com entusiasmo 14 postos de saúde distribuídos pelo Brasil, isso tudo graças à benemerência do Guilherme Guinle. Ele procurou o Guilherme, mostrou os planos dele e as dificuldades que tinha com o governo, e o Guinle resolveu colaborar. No Brasil, muito raros são os Guilherme Guinle.

Quando o Evandro morreu, eu tive os piores anos da minha vida. Porque eu trabalhava em dois lugares, trabalhava de manhã cedo, de 7 até meio-dia no instituto. Ia para o hospital, fazendo o serviço de Evandro e, depois de almoçar lá, eu saía, ia para a cidade, para o laboratório na Praia Vermelha, ficava até 8 e meia, 9 horas, e saía exausto. Foi a ocasião em que eu apanhei uma tuberculose. Fui obrigado a passar seis meses em Barbacena, e lá conheci uma pessoa que teve uma grande importância na minha vida: Georges Bernanos, um médico católico rebelde francês. Ele tinha se exilado da França e, chegando aqui, tinha sido amparado pelo meu cunhado. $O$ que eu devo a Bernanos? A liberação de uma certa caturrice católica que eu tinha. Hoje eu sou, posso dizer, usando uma palavra do Bernanos, um católico livre. O que não quer dizer que eu não seja pecador.

Mas, voltando ao Guinle, quando eu fui falar com ele, ele disse: "Já que você organizou isso com o Evandro, agora eu vou cuidar de seu laboratório". De modo que toda vez que eu precisava de algo e não recebia da universidade, eu ia falar com o Guinle e ele me ajudava. Ele ajudava muita gente, não foi só a mim, ajudava também na área artística. E aí comecei de alma nova para fazer o Instituto de Biofísica. Era bem melhor quando era naUrca. Em minha autobiografia, Lm A prendizde Ciência, ${ }^{42}$ eu conto alguns

\footnotetext{
42 CHAGAS FILHO, C. Um Aprendiz de Ciência. Rio de Janeiro: Editora Fiocruz, Nova Fronteira, 2000.
} 
dos fatos que contei para você e outros mais. Será publicado em breve. Esse livro, aliás, se tornou possível graças ao Paulo Gadelha. Considero o Gadelha das pessoas mais interessantes que conheço. Tenho por ele uma admiração incrível, tanto que só o chamo de Paulinho. No livro, uma das passagens de que eu mais gosto é quando falo da Academia Pontifícia de Ciências do Vaticano. Sobre o processo do Galileu, quando dizem que eu fui o responsável, retruco que era uma coisa que tinha de acontecer. $\mathrm{Na}$ verdade, eu não sou um especialista em Galileu, quem me chamou a atenção para o problema na academia foi o Cardeal König da Áustria. Ele achava indispensável rever o processo do Galileu, acho que ele já havia tentado e não tinha conseguido, sabe? O mérito todo cabe a Paulo VI. Paulo VI teve a coragem de substituir um clérigo que presidia a academia e se aposentara por mim, o primeiro não clérigo. Em meu livro, digo que, na verdade, não sei quem me indicou ao Papa, mas tenho a desconfiança de que foi Dom Eugênio Sales e talvez o cardeal Benelli, que conheci quando eu era embaixador pela Unesco e ele, o representante do Vaticano. Lá, nós discutimos muito sobre problemas religiosos, de modo que eu acho que foi ele também, pois ele foi para Roma e uns tempos depois eu fui convidado. De uma maneira extraordinária. Eu estava vindo de uma sessão, se não me engano, em Genebra, e tinha feito uma coisa deliciosa: visitamos a Borgonha, e em cada parada eu e a minha mulher, hum, experimentávamos maravilhas, uma verdadeira degustação. Chegamos às 5 horas da manhã em Paris, nós tínhamos alugado um apartamento lá. Assim que nos instalamos, era ainda muito cedo quando recebi um telefonema do núncio apostólico em Paris, Righi-Lambertini, que me convidava para estar às 11 horas em seu escritório. Quando chegueilá, sem muita demora, ele disse assim: "Chamei-o aqui porque - Papa está convidando o senhor para a presidência da Academia Pontifícia de Ciências". Eu perguntei: "O senhor tem certeza disso?" Fiquei tão fora de mim, tão fora de mim, que ele afirmou: "Não só o Papa enviou um telegrama que aqui está, manifestando o convite, como me disse onde o senhor poderia ser encontrado em Paris, em tal lugar assim, assim". E foi 
tudo muito rápido, logo terminei um curso que estava dando em Paris e, semanas depois, embarquei para Roma, onde, a partir daquela época, vivi 16 anos maravilhosos.

Em relação ao Instituto de Biofísica atual, uma de suas linhas de pesquisa mais relevantes é a protozoologia, iniciada pela Dra. Hertha Mayer. O grupo de protozoologia é muito bom. O cultivo de protozoários em cultura de tecidos foi iniciado lá. Estão buscando encontrar uma substância ativa contra - Trypanosoma cruzi. E muitos perguntam: "Mas como, protozoologia na Biofísica?" Há duas respostas: a primeira é que a biofísica é o que eu quero estudar; a segunda é que, como se trata de um laboratório de biologia, ele tem de ter animais, e o Trypanosomacruzi é um animal que utilizamos para experiência como uma outra cobaia qualquer, macacos e peixes elétricos.

Embora eu não tenha relatado a você fatos em que o acaso ocorre, é aquela história: que ele existe, existe. Agora, para o acaso se revelar, é necessária uma coisa muito importante: a sabedoria do pesquisador, o preparo do pesquisador. Sem que seja um pesquisador muito preparado, completo, não há acaso, a experiência passa ao largo. 


\section{Carlos Chagas Filho ${ }^{43}$}

Dr. Carlos Chagas Filho nasceu no Rio de Janeiro em 1911. Médico, filho do também médico e cientista Carlos Chagas, teve a ciência como berço, tornandose, em suas próprias palavras, "um dependente da ciência". Como dizia, "tenho a ciência dentro da pele". Desde criança, freqüentou o ambiente cien-tífico e cultural do IOC, onde completou a sua formação de pesquisador, tornando-se biofísico de renome internacional. com apenas 27 anos, foi aprovado no concurso para a cátedra de física biológica da Faculdade Nacional de Medicina, onde oito anos depois, em 1945, criou o Instituto de Biofísica, hoje Instituto Carlos chagas Filho/UFRJ, um dos mais produtivos centros de pesquisa do Brasil. Desde o início, sempre equipou e modernizou o instituto, com recursos da Fundação Rockefeller, da Fundação Ford e de fontes nacionais, tendo também criado o curso de pós-graduação em biofísica. Neste ambiente, estimulou a formação de excelentes pesquisadores e manteve permanente intercâmbio com renomados cientistas internacionais, promovendo trabalhos em colaboração. Lá também foi um admirável professor durante toda a vida: até 1999, ministrou um curso na pós-graduação; nos últimos anos, trabalhava em cadeira de rodas. Foi embaixador do Brasil na Unesco entre 1966 e 1970, e integrou o comitê de organização da Primeira

\footnotetext{
${ }^{43}$ Biografia composta com dados extraídos do livro Meu Pai.
} 
Conferência Mundial sobre o Meio Ambiente. Participou da comissão de Salvação de Veneza, como único representante latino-americano. Como presidente da Academia Pontifícia de Ciências do Vaticano, cargo que exerceu por quase duas décadas (1971-1988), mobilizou a comunidade científica pela paz e pelo desarmamento atômico e propôs a revisão do processo da Inquisição que condenou Galileu Galilei, a qual resultou em sua absolvição. como homem de letras, tornou-se membro da Academia Brasileira de Letras. Foi também membro da Academia Brasileira de Medicina, da Academia Brasileira de Ciências, da Academia de Ciências de Paris e de outras instituições científicas e universitárias nacionais e internacionais. Foi condecorado com sete grã-cruzes e recebeu muitas outras homenagens e prêmios. Publicou mais de duzentos trabalhos científicos. É autor de um memorável livro sobre Carlos Chagas, intitulado Meu Pai. Faleceu aos 89 anos, em fevereiro de 2000 , após ter recebido o Prêmio Oswaldo cruz pela sua valiosa e prestigiosa colaboração à Fiocruz e à ciência brasileira, deixando no prelo a sua autobiografia - Um Aprendiz de ciência -, agora publicada. 